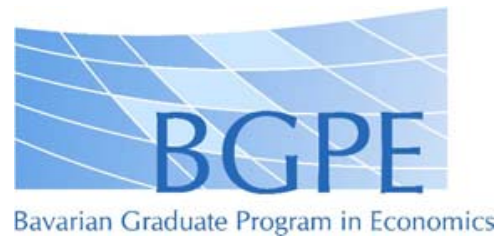

BGPE Discussion Paper

No. 71

\title{
Modelling the folk theorem of spatial economics: a heterogeneous regional growth model
}

\section{Torben Klarl}

May 2009

ISSN 1863-5733

Editor: Prof. Regina T. Riphahn, Ph.D.

Friedrich-Alexander-University Erlangen-Nuremberg

(c) Torben Klarl 


\title{
Modelling the folk theorem of spatial economics: a heterogeneous regional growth model
}

\author{
Torben Klarl \\ Department of Economics, University of Augsburg, \\ Universitätsstraße 16, D-86159 Augsburg, Germany \\ e-mail: torben.alexander.klarl@wiwi.uni-augsburg.de \\ Tel.: $++49(0) 821-598-4177$ \\ Fax: $++49(0) 821-598-4229$
}

May 4, 2009

\begin{abstract}
During the last year, the research field of spatial economic has rapidly increased. There is consensus that the economic performance of a region depends not only on its own potential, but also on the development of their neighbouring regions. Knowledge spillovers, which are non constant over space, should influence the evolution of the region specific productivity. The so called "folk theorem of spatial economics" states, that increasing returns to scale are essential for explaining the uneven economic distribution of specific economic activity, which implies that knowledge spillover, agglomeration and distribution of per capita productivity are closely linked. Thus, the aim of this paper is, to introduce a spatial regional growth model, which links first time knowledge spillover, agglomeration, distribution of per capita productivity and the grasp of spillovers. Further, it is shown in a simulation study, how different regimes of returns to scale and grasps of knowledge affect agglomeration and distribution of per capita productivity. One of key findings is, that grasp of knowledge affects dynamic distribution of per capita productivity. Moreover, the simulation study particularly finds support for the "folk theorem of spatial economics".

Keywords: Spatial Economics, Agglomeration, Spatial knowledge spillovers, New economic geography, Regional growth
\end{abstract}

JEL Classification Number: R11, R12, F43 


\section{Motivation}

It is an undisputable fact that knowledge and technological change are the driving forces for long run economic growth. Additionally, endogenous growth theory tells us that knowledge spillovers are necessary for long term growth of high-income regions. Several contributions regarding this topic have been published during the last years. (Lucas, 1988), (Krugman, 1991) and (Romer, 1986), for instance have explicitly focused on the accumulation of new knowledge in context of new growth theory. Their key finding is, that endogenous accumulation of knowledge is the surety of per capita income growth. These approaches have in common that they focus on convexities in production process ${ }^{1}$. For instance, convexities in production can arise from positive externalities caused by learning-by-doing, human capital accumulation and the supply of governmental goods.

As argued by (Keilbach, 2000), knowledge spillovers can be treated as a special type of positive externalities and, moreover, is one motivation for positive returns to scale in an aggregate production function approach which was first used by (Griliches, 1979).

At the latest as European leaders met in Lisbon 2003 and defined the goal of becoming "the most dynamic and competitive knowledge-based economy in the world" by 2010 the term it can be said without any limitations that the knowledge-based economy has gained much attraction, not only in research but also in politics. Today, the creation and diffusion process of knowledge is the focal point of research, because "knowledge is the most important strategic resource and learning the most important process" 2 . But what is knowledge? Well, the term knowledge is often used in scientific publications, but it is sometimes confounded with the term "information". It must be clear that knowledge comprises the individual specific abilities which can be used to solve more or less strategic problems underpined with a pool of information. As pointed out by (Krugman, 1991) "[k]nowledge flows are invisible; they leave no paper trail by which they may be measured and tracked[...]". Information

\footnotetext{
${ }^{1}$ Refer on (Krugman, 1991) for this topic for instance.

${ }^{2}$ (Morgan, 1997), p. 493.
} 
instead, is more or less visible. It can interpreted as the collection of knowledge, for instance the collection of data. Hence, when talking about knowledge, we often don't know what we know. Thus, knowledge cannot be measured directly, as other production inputs such as the stock of capital, for instance. The consequence is, that we have to find proxies for this knowledge, for instance human capital or data of patent citations. But doing so, we have to macerate the strict distinction between information and knowledge. That should be kept in mind when talking about the outstanding role of knowledge for economic growth.

Additionally, it is difficult to extract the incentives and resources of knowledge creation and diffusion. As argued by (Rosenberg, 1982), the so called "black box" of innovation which can be described by inherent loops and feedback processes, is also suitable to describe the difficulties of how to identify the source of knowledge creation and dissemination. Given we know the source of knowledge creation, how can we describe concisely the way of how knowledge is transfered from sender to receiver? Is it always the case, that transmitted knowledge can be interpreted correctly by the receiver and more important, is it possible at all to transfer knowledge? The questions we have to ask are therefore, first, is it always true that knowledge diffusion is an unlimited process regarding space, and second, does knowledge transmission depend also on the kind of knowledge?

To answer these questions, we have to think about the kind of knowledge we are talking about. For example, if knowledge is tacit than face-to-face communication or spatial proximity is a necessary condition for knowledge diffusion. On the other hand, if knowledge is codified, than modern communication facilities can be used to transfer knowledge from sender to receiver. Thus codified knowledge is less space depended than tacit knowledge as highlighted by (Anselin et al., 1997). Therefore, we should expect that tacit knowledge dissemination is different from explicit knowledge dissemination with respect to time and space. As mentioned by (Maskell and Malmberg, 1999) tacit knowledge is a key factor for new innovations and thus spatial proximity, which is close related to tacit knowledge should be acknowledged. 
From this point of view, it is plausible not only to focus on time and the kind of knowledge, when integrating knowledge diffusion in a growth model context for example, but also to consider a possible space limitation of knowledge transfer.

It is rather intuitive, that spatial barriers of knowledge diffusion can be used as an argument for income and production differentials between regions. That should be considered as one reason why we observe cluster and agglomeration in economic long run growth. Regions (take cities for example) which are more productive and supply a higher life quality are more attractive for innovative companies. Consequently, these regions become more attractive again and this process leads to a more and more decreasing productive differential. It is not a surprising fact, that economic growth and agglomeration are positive correlated (Baldwin and Martin, 2003). Hence, growth differentials are enforced by knowledge capital concentration. As mentioned by (Fujita and Thisse, 2002), knowledge spillovers can be interpreted as a source for sustainable regional growth, given decreasing returns of learning are excluded.

If we argue that spatial patterns are worth investigating, it is necessary to ask the question how knowledge spillovers affect agglomeration. To answer this question we could argue that cities or densely populated regions may have positive effects on their productivity due to so called Marshallian externalities. (Marshall, 1920) mentioned, that so called externalities are necessary for economic agglomeration and therefore create a so called look-in effect ${ }^{3}$ : "When an industry has thus chosen a location for itself, it is likely to stay there long: so great are the advantages which people following the same skilled trade get from near neighbourhood to one another. The mysteries of the trade become no mysteries; but are as it were in the air, and children learn many of them unconsciously. Good work is rightly appreciated, inventions and improvements in machinery, in processes and the general organization of the business have their merits promptly discussed: if one man starts a new idea, it is taken up by others and combined with suggestions of their own; and thus it becomes the source

\footnotetext{
${ }^{3}$ (Fujita and Thisse, 2002), p. 7.
} 
of further new ideas." 4 Of course, the justification of agglomeration by Marshall is primarily based on trade arguments but can easily be expanded to other factors, which influence the decision of where to situate a location, as mentioned above. (Kahnert, 1998) found that knowledge intensive processes are agglomerated in dense regions, while less knowledge intensive processes are situated in more peripheral regions. Thus, knowledge spillovers cause externalities and force agglomeration and as a consequence, as pointed out by (Scotchmer and Thisse, 1992) leads to uneven geographical distribution of economic activity.

Hence, from a theoretically driven view, increasing returns to scale, agglomeration and distribution of economic numbers, for instance per capita productivity are closely linked with space. Although, the link of technological innovations and knowledge diffusion for technological growth is acknowledged in growth literature ${ }^{5}$, the role of knowledge diffusion is only partly considered. Some of the North-South trade literature on diffusion and technological progress ${ }^{6}$ consider feedback effects between the North and the South in the steady state, but an analysis of the transitional dynamics for either region is missed. (Barro and Sala-I-Martin, 1997) indeed derived transitional dynamics for the South but feedback effects are excluded due to the effect of no trade of intermediate goods. Thus, a transition path for the North cannot be derived. The communality of this strand of literature is only focused on two country or two region models, which consists of a rich North and a poor South or a core and a peripheral country. From this perspective, those types of models are less suitable to investigate the link of increasing returns to scale, agglomeration and distribution of economic numbers because of the simple reason: in a two country framework, it is not reasonable to investigate agglomeration effects when referring to regions. One of the factors, why multiple country or regional focused growth models are less attractive or gained less attention could be the fact that such growth

\footnotetext{
${ }^{4}$ (Marshall, 1920), p. 225.

${ }^{5}$ Refer to (Romer, 1986), (Romer, 1990) and (Krugman, 1991) for instance.

${ }^{6}$ Refer to (Krugman, 1979), (Dollar, 1986), (Grossman and Helpman, 1991b), (Grossman and Helpman, 1991a), (Rivera-Batiz and Romer, 1991), (Barro and Sala-I-Martin, 1997) and (Glass, 1997).
} 
models become very complex and cannot solved analytically and only numerically solutions remain.

For this reason, the relevant literature which investigates the link between increasing returns to scale, agglomeration and distribution of economic numbers is heavily empirical orientated and is sometimes more or less ad hoc. To investigate spatial agglomeration effects empirically, one has to refer to tools from a toolbox which can be summarized with "spatial econometrics", a term widely used in New Economic Geography (NEG) ${ }^{7}$. (Anselin, 1988)'s book can be described as the first comprehensive introduction to spatial econometrics. In contrast to spatial statisticians, where pure data or data based approaches are in the front, the spatial econometricians deal with model-funded approaches, based upon a theoretical model. However, the commonality of the two perspectives is the acceptance of the existence of spatial stochastic processes.

Although, from an empirical view, there has been made much progress in explaining the link between increasing returns to scale, agglomeration and distribution of economic numbers. But there are still limitations especially when talking about the grasp of knowledge spillovers and knowledge diffusion.

First, less attention is concentrated on the fact, that knowledge diffusion is not a constant process over space. Often it is assumed that only the nearest neighbour has a significant influence on economic growth, whereas farther away neighbours do not exert any economic influence, or more technically spoken, often it is assumed that knowledge diffusion follows a spatial $\mathrm{AR}(1)$ or spatial MA(1) process and second or higher order effects or a combination of both are neglected. This assumption seems to be to strict. Instead of ignoring higher order effects of spatial influence, one should insert them into a model framework, because neglecting them could lead to an underestimating of spatial influence. Further, this second or higher order processes should not be treated as a constant extrapolation, but rather as non constant function over space. Hence, it is reasonable to assume that more contiguous neighbours have a direct and stronger influence than less contiguous neighbours.

\footnotetext{
${ }^{7}$ For an overview of NEG refer to (Krugman, 1998a) and (Krugman, 1998b) for example.
} 
In most of the existing empirical studies the grasp of knowledge spillovers has only gained limited attention. (Anselin et al., 1997) and (Anselin et al., 1997) are two of the few studies how mentioned concrete numbers of knowledge spillover scope. (Anselin et al., 1997) found by investigating the influence of university related research and private research and development $(\mathrm{R} \& \mathrm{D})$ effort on of knowledge transfer that a significant positive effect can be detected within a 50 mile radius of metropolitan statistical areas (MSAs) only for the university research. For private R\&D such an significant effect could not be detected. (Anselin et al., 1997), with a similar setup as (Anselin et al., 1997) additionally have shown, that not only spillovers within MSA but also between MSA can be found. The key cognition of the latter mentioned study is, that without exact geographical distance measures, it can be shown that spatial influence is bounded locally. (Audretsch and Mahmood, 1994) have shown on patent basis for 59 US metropolises, that knowledge spillovers are limited towards the metropolises' boarders. They come to this conclusion because they found that only for research institutes which are settled within a metropolis, significant knowledge spillovers can be detected, whereas for research institutes, settled in each metropolis related country, no such effects could be found.

Second, within the specification of spatial models, spatial heterogeneity is mostly missed. It is sometimes ignored, that spatial effects can appear as two types: the one type is spatial dependence, the other is spatial heterogeneity. Spatial dependence, which is consitently assumed in the above mentioned studies, is mainly caused by problems of measuring that are caused by spatial spillovers and spatial externalities. In contrast to spatial dependence, spatial heterogeneity means that spatial effects are not uniformly distributed across space and outliers could exist. From a standard econometricians toolbox, this could be seen as a spatial kind of heteroscedasticity. Although several arguments militate in favour that spatial heterogeneity matters ${ }^{8}$,

\footnotetext{
${ }^{8}$ (Anselin, 1988) for instance comment on page 13 with respect to importance of spatial heterogeneity in econometricians work, that "several factors, such as central place hierarchies, the existence of leading and lagging regions, vintage effects in urban growth [...] would argue for modeling strategies that take into account the particular features of each location (or spatial unit)."
} 
this aspect is not "seen as a serious problem in spatial regression" ${ }^{9}$. One reason could be, that spatial econometrics, if we refer to theoretical econometrics, is still a developing discipline.

But what should be done, if spatial dependence, spatial heterogeneity or a combination of both types is relevant and further a set of possible $\operatorname{AR}(\mathrm{p}), \mathrm{MA}(\mathrm{q})$ or $\operatorname{ARMA}(\mathrm{p}, \mathrm{q})$ processes with order $p$ and $q$ respectively, are suitable in model context? Given, our model is correctly specified, than standard econometrics tells us, that parameter estimates are insufficient if spatial heterogeneity is ignored, although it is relevant. But given, the model is based on a wrong choice of $\operatorname{AR}(p), M A(q)$ or $\operatorname{ARMA}(\mathrm{p}, \mathrm{q})$ terms, then our model is wrong specified. Of course, the latter problem is the more serious one.

Although, model selection should be taken seriously, we frequently find that empirical based studies using tools from spatial econometrics, based on ex ante conceptions of a spatial model. This means, a model selection is often defaulted or, if done, it is based mainly on a limited class of spatial processes, which commonly include the decision of relying on a spatial $\mathrm{AR}(1)$ or spatial $\mathrm{MA}(1)$ process based on the assumption of spatial homogeneity. There are, to best of my knowledge only a few papers which cover the aspect of spatial model choice. ${ }^{10}$

Thus, traditional or frequentest econometrics approach suffers from two reason in context of spatial econometrics: first, the models and the underlying estimation methods assume spatial homogeneity, and second, model selection is rather heuristic. For that reasons, Bayesian methods have been prevailed and proved in spatial econometric application. The key difference between frequentest and Bayesian methods are that the latter treat the coefficient vector of estimators itself as random, whereas frequentest say that the resulting estimates of the coefficient vector is random. Bayesian methods hold a great deal for several reasons: for instance, first, it is possible to model hierarchy of place or regions, second, one can integrate a more or less systematic change of variance over space, and thus spatial heterogeneity and

\footnotetext{
${ }^{9}$ (Keilbach, 2000), p. 122.

${ }^{10}$ For instance refer to (Hendry, 1979), (Florax et al., 2003) and (Hendry, 2006) for an intensive discussion regarding model selection methods.
} 
third it is possible to acknowledge a hierarchy of regions or places. Bayesian methods can incorporate these ideas because of their underlying concept as prior information complements existent sample data information, whereas frequentest methods can solely rely on latter mentioned. As mentioned before, although Bayesian methods seem to be very attractive, their usage in application is very limited. On the other side, frequentest methods are, if they only limited to the spatial dependence case, and therefore assume spatial homogeneity, lead to insufficient parameter estimates. Anyway, a more or less large research agenda for both, spatial econometrics and spatial statistics remains.

From the discussion above, we see that two different arguments regarding productivity growth are discussed in the relevant literature: on the one hand, the (theoretically) role of technological innovations and knowledge diffusion for technological growth $^{11}$, and on the other hand the (empirical) role of spatial agglomeration on long run productivity growth ${ }^{12}$. The point is, that the first mentioned strand does discuss growth implications of knowledge diffusion in a less suitable frame when focusing on distribution questions and agglomeration, while the latter strand suffers more or less from theoretical fortification.

Hence, these two approaches are more or less discussed in isolation rather to be combined and to investigate the relationship between knowledge diffusion, agglomeration and growth. This topic has gained less attention in relevant literature, although (Fujita and Thisse, 2002) mentioned that "increasing returns to scale (IRS) are essential for explaining geographical distributions of economic activities"13.

There is to best of my knowledge only one study, which tries to bridge the two approaches: (Keilbach, 2000) has investigated the role of knowledge for German "Kreise" 14 both empirically and theoretically within a (Romer, 1986) context. He found, that increasing returns to scale lead to significant cluster effects. Further, he found on basis of several production functions estimations, that spatial dependence

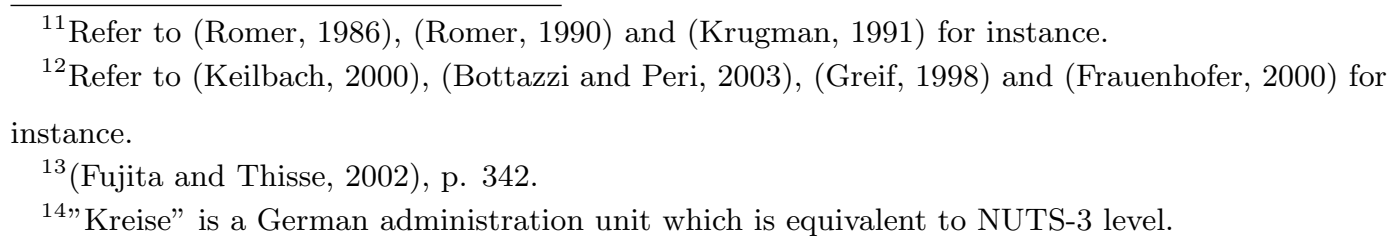


has a significant influence on labour productivity. But it has to be mentioned, that (Keilbach, 2000) assumes explicitly spatial homogeneity and only first order spatial effects, both in his theoretical and empirical studies. Further, using "Kreise" as regions could lead to spatial dependence per definition, due to the fact that "Kreise" are the smallest entity of regions for the case of Germany, and thus stream of commuters can lead to biased estimations of spatial effects by construction.

Thus, one intention of this paper is, to include the economic variable space in a simple theoretical hybrid growth model, which core is based on to the model of (Mulligan and Sala-I-Martin, 1993), (Uzawa, 1965) and (Lucas, 1988). The purpose of the theoretically derived model is to derive a theoretical growth orientated justification of the "folk theorem of spatial economics" 15 , that "increasing returns to scale (IRS) are essential for explaining geographical distributions of economic activities" ${ }^{16}$. In the theoretical model it is assumed that regions are learning regions which means that low-income regions can catch up to high-income regions. This spatial catch up process has not been acknowledged in growth theory so far. The implication is, that knowledge is not completely tacit but contains a certain public good character as highlighted by (Brezis and Krugman, 1993). On the other site, one has to acknowledge the fact, that spatial influence is limited and not constant over space. This is a consequence of the (Fujita and Thisse, 2002) thesis explaining economic clusters. Thus, the aim of this paper is first, to investigate on the basis of a hybrid regional growth model, how knowledge spillovers and agglomeration are related in space. Second and closely related to the first aim is, to study the dynamic behaviour of per capita distribution over regions and thus over space. For this purpose Cellular Automaton (CA) simulation technique is employed.

\section{Theoretical model}

The aim of the theoretical model is to find support or not for the fact, that "increasing returns to scale (IRS) are essential for explaining geographical distributions of

\footnotetext{
${ }^{15}$ Refer to (Scotchmer and Thisse, 1992).

${ }^{16}$ (Fujita and Thisse, 2002), p. 342.
} 
economic activities" 17 and thus to justify the "folk theorem of spatial economics" 18 . The model further assumes that spatial dependence over space is not constant. Because the model could become very complex, a Cellular Automaton programming technique is consulted to simulate spatial patterns. The next section deals with the empirical conversion of the theoretical model context.

\section{$2.1 \quad$ Setup}

This section deals with the setup of a discrete spatial growth model, which links knowledge creation, spatial knowledge diffusion and productivity to investigate the link of knowledge, agglomeration and growth. For this purpose, a two sector model which is similar to the model proposed by (Lucas, 1988) is set up and expanded in several ways as laid out in the this section.

Assume a world of $i=\left\{1,2, \ldots, N_{i}\right\}$ regions which are distributed randomly over the entire space of the world. Every region is heterogeneous in the sense that it can be characterized by a specific labour productivity $y_{i}$ which is different in every region $i$. Furthermore, every region $i$ has different neighbours $j=\left\{1, \ldots, N_{j}\right\}$.

As mentioned above, two sectors are considered in the model. The first sector is the knowledge production sector. This sector produces exclusively knowledge with a specific neoclassical production technique $Q$. Moreover it is assumed, that every region $i$ produces its own knowledge stock $W^{i}$. For the production technique we can write for region $i$ in $t=\{1,2,3, \ldots, T\}$

$$
Q_{t}^{i}\left(K_{t}^{i}, W_{t}^{i}, L_{t}^{i}\right)=B\left[a_{K} K_{t}^{i}\right]^{\gamma}\left[a_{W} W_{t}^{i}\right]^{\phi}\left[A_{t}^{i} L_{t}^{i}\right]^{\kappa}
$$

with $W_{t}^{i}$ as the knowledge stock, $K_{t}^{i}$ as the capital stock and $L_{t}^{i}$ as unskilled workforce of region $i . B>0$ is a global shift parameter and $a_{K} \in(0,1)$ and $a_{W} \in(0,1)$ stand for the global fractions of capital and knowledge stock used for production of new knowledge. $\gamma \in(0,1), \kappa \in(0,1)$ and $\phi \in(0,1)$ are the corresponding production elasticities. Thus, every region $i$ produces with the same production technique $Y_{t}^{i}$

\footnotetext{
${ }^{17}$ (Fujita and Thisse, 2002), p. 342.

${ }^{18}$ Refer to (Scotchmer and Thisse, 1992).
} 
in the knowledge production sector. $A^{i}$ is a time dependent shift parameter with constant growth rate $g_{a}^{i}$, so that $A_{t+1}^{i}=\left(1+g_{a}^{i}\right) A_{t}^{i}$.

As one can easily see from equation 1 is that unskilled workforce is entirely used in the sector of knowledge creation and cannot be used in the goods sector. This assumption seems to be strict at first glance, but the focus on this model is to work out the link of knowledge, agglomeration and growth. Of course, we can expand the model in this sense, that a fraction, say $a_{L}$ can also be employed in the goods sector. But the implications of this model remain unaffected by this modification.

The goods sector is formulated similarily to the knowledge producing sector with the exception that only knowledge and capital are needed to produce output $Y_{t}^{i}$. For that reason one can write the production function $Y_{t}^{i}$ as follows:

$$
Y_{t}^{i}\left(K_{t}^{i}, W_{t}^{i}\right)=\left[\left(1-a_{K}\right) K_{t}^{i}\right]^{\alpha}\left[\left(1-a_{W}\right) W_{t}^{i}\right]^{\beta} .
$$

Thus, every region $i$ produces with the same production technique $Y_{t}^{i}$ in the goods sector. As one can see from equation 2 the good is produced via "transformed" labour through knowledge capital generation and capital stock $K_{t}$. For the labour productivity in efficiency units $y_{t}^{i 19}$ we can write:

$$
y_{t}^{i} \equiv \frac{Y_{t}^{i}}{A_{t}^{i} L_{t}^{i}}=\left[\left(1-a_{K}\right) k_{t}^{i}\right]^{\alpha}\left[A_{t}^{i} L_{t}^{i}\right]^{\alpha-1}\left[\left(1-a_{W}\right) W_{t}^{i}\right]^{\beta},
$$

with $k_{t}^{i}=\frac{K_{t}^{i}}{A_{t}^{i} L_{t}^{i}}$. As usually, it is further assumed that labour is growing with constant rate $g_{n}^{i}$ so that $L_{t+1}^{i}=\left(1+g_{n}^{i}\right) L_{t}^{i}$.

In the next step we have think about the integration of space in our model. This is done in several ways. First we have to formulate a rule for the unskilled labour. It is assumed that unskilled labour is not very mobile and mostly bounded to its origin region due to social connections as family, friendship relations etc.. Labour from a region $i$ is only emigrating if it offers the lowest wage payed in the goods sector in the set of neighbours. More technical, a fraction $\theta L_{t}$ will leave region $i$ in $t$. On

\footnotetext{
${ }^{19}$ In the following "labour productivity" and "labour productivity in efficiency units" are used as synonyms.
} 
contrary, if region $i$ offers the highest wage in the set of neighbours, then labour force from neighbouring regions is immigrating in region $i$. Again more technical, a fraction $\theta \sum_{j} L_{t}^{i}$ will immigrate to region $i$. Otherwise due to strong social ties, no migration movement occurs. Therefore we can formulate the following transition rule:

$$
L_{t+1}^{i}=\left\{\begin{array}{cl}
\left\{\theta \sum_{j} L_{t}^{j}+L_{t}^{i}\right\}\left(1+g_{N}\right) & \text { if } w_{t}^{i}=w_{t}^{\max } \\
L_{t}^{i}(1-\theta)\left(1+g_{N}\right) & \text { if } w_{t}^{i}=w_{t}^{\min } \\
L_{t}^{i}\left(1+g_{N}\right) & \text { otherwise }
\end{array} .\right.
$$

with $w_{t}^{\max }$ as the maximum wage payed the set of neighbours and region $i$, and with $w_{t}^{i n}$ as the minimum wage payed the set of neighbours and region $i$. Assumption 4 can also be interpreted as the fact that an unskilled worker is not perfectly informed about wage conditions in the entire world but only within the neighbourhood of his home region $i$. If the wage is situated between $w^{\text {min }}$ and $w^{\text {max }}$, then there is no incentive to leave the home region $i$. Of course, if $\theta=0$ no migration can be observed, the states of the system are entirely absorptive with respect to space but not with respect to time, because $L_{t}^{i}$ is constant over space, but not over time. If $g_{n}^{i}$ is also set to zero, $L_{t}^{i}$ is constant over time and over space.

On contrary to the labour market which is more local, the capital market is organized globally and capital is mobile over the entire space of our world. This means that an a priori fraction of the investments $\varphi$ from region $i$ flows in that region $j$ which exhibits a higher net capital productivity $r_{t}^{j}$ compared to the mean capital productivity $\bar{r}$. The fraction $(1-\varphi)$ is invested in the region of origin. Although, the flow is not regionally bounded, the factor $\varphi \in[0,1]$ weights the neighbouring investments $s Y_{i} \varphi$ of region $i$ to acknowledge possible capital transfer restrictions, which may be imposed by politics or can be intrinsicly motivated. Thus, the transition rule for the capital is formulated as follows:

$$
K_{t+1}^{i}=\left\{\begin{array}{cc}
s\left[\left(\sum_{j} Y_{t}^{j} \varphi \chi_{i}\right)+Y_{t}^{i}\right]+\left(1-\delta_{K}\right) K_{t}^{i} & \text { if } r_{t}^{i}>\bar{r} \\
(1-\varphi) s Y_{t}^{i}+\left(1-\delta_{K}\right) K_{t}^{i} & \text { if } r_{t}^{i}<\bar{r}
\end{array}\right.
$$


with $\varphi \in[0,1]$ as the fraction of investment which is made in neighbouring regions, $\delta \in[0,1]$ as the depreciation rate on capital and $\chi_{t}^{i}$ represents the weighting measure for capital flows. To obtain a weighting measure of how much capital flows a priori to neighbouring regions we construct an endogenous weighting measure which depends on the relationship of own marginal product of capital and the sum of neighbouring marginal products of capital. This can be transfered into the following equation:

$$
\chi_{t}^{i}=\left\{\begin{array}{cl}
\frac{r_{t}^{i}}{\sum_{j} r_{t}^{j}} & \text { if } r_{t}^{i}>\bar{r} \\
0 & \text { if } r_{t}^{i}<\bar{r},
\end{array}\right.
$$

which implies $\chi_{t}^{i} \in(0,1)$. From equation 6 we can see that even if $\chi \in(0,1)$ is positive for a region $i$, capital restriction in other regions $j$ may hinder the flow to the own region $i$. For example, set $\varphi=0$, then region $i$ can reinvest only its own savings, even if $\mathrm{r}_{t}^{i}>\bar{r}$.

If we assume, that further increase of investment $I_{t}^{i}$ is associated with higher investment expenditures, we may have to think about capital costs $\phi\left(\frac{I_{t}}{K_{t}}\right)$. A priori, capital costs should play a crucial role not only for home investments but also for neighbhouring investments. For that reason, we formulate

$$
\phi\left(\frac{I_{t}^{i}}{K_{t}^{i}}\right)^{i}=\left\{\begin{array}{cl}
\left(\frac{1}{1-\zeta}\right)\left(\frac{s\left(\sum_{j} Y_{t}^{j} \varphi \chi_{i}+Y_{t}^{i}\right)}{K_{t}^{i}}\right)^{(1-\zeta)} & \text { if } r_{t}^{i}>\bar{r} \\
\left(\frac{1}{1-\zeta}\right)\left(\frac{s Y_{t}^{i}(1-\varphi)}{K_{t}^{i}}\right)^{(1-\zeta)} & \text { if } r_{t}^{i}<\bar{r}
\end{array},\right.
$$

with $\zeta>0$. Thus for the transition rule of capital stock $K_{t}^{i}$ we have to choose the following notational form:

$$
K_{t+1}^{i}=\phi\left(\frac{I_{t}}{K_{t}^{i}}\right) K_{t}^{i}+(1-\delta) K_{t}^{i}
$$

We have to note, that $\phi(\cdot)$ is a concave and decreasing function its relevant argument and if one sets $\phi\left(\frac{I_{t}}{K_{t}}\right) \equiv\left(\frac{s\left(\sum_{j} Y_{t}^{j} \varphi \chi_{i}+Y_{t}^{i}\right)}{K_{t}^{i}}\right)$ or $\phi\left(\frac{I_{t}}{K_{t}}\right) \equiv\left(\frac{s Y_{t}^{i}(1-\varphi)}{K_{t}^{i}}\right)$ one obtains equation 5 together with equation 8 . 
In the next step we have to create a direct link between knowledge spillovers and labour productivity. For this scope, we assume that a region $i$ will benefit from "knowledge creation" of other regions $j$. Hence, the knowledge stock $W_{t+1}^{i}$ is determined by the production of knowledge $Q_{t}^{i}$ and the weighted spillovers $\sum_{j} W_{t}^{j}$ from neigbouring regions $j$. Therefore, we can formulate a transition rule for the knowledge stock $W_{t+1}$ :

$$
W_{t+1}^{i}=Q_{t}^{i}+\iota_{i}^{t} \sum_{j} W_{t}^{j}+\left(1-\delta_{W}\right) W_{t}^{i}
$$

whereas $\iota \in[0,1]$ is an endogenous measure of degree of spillovers and $\delta_{W}$ represents the deprecation rate on knowledge. It is assumed that the degree of spillovers ${ }_{t}^{i}$ can be modeled as a function of the maximum stock of knowledge which is available in the economy $W_{t}^{\max }$ and the region specific knowledge stock $W_{t}^{i}$. Thus, the spillover degree is the greater the smaller the difference of $W_{t}^{\max }$ and $W_{t}^{i}$ is. Accordingly, we can write

$$
\iota_{t}^{i}=1-\left\{\frac{W_{t}^{\max }-W_{t}^{i}}{W_{t}^{\max }}\right\}
$$

which is $\in[0,1]$. If $W_{t}^{\max }-W_{t}^{i}=0$ then $\iota_{t}^{i}$ takes its maximum level of one. On contrary, $\iota_{t}^{i}=0$ if $W_{i}^{t}=0$.

Not only $W_{t}^{i}$ accounts for spillovers but also $Y_{t}^{i}$ itself. It is known from the convergence debate that emerging countries should grow faster if they have not reached their balanced growth path. If we define an endogenous technological gap as $\Theta_{t}^{i}=$ $\frac{\bar{Y}_{t}-Y_{t}^{i}}{\bar{Y}_{t}}$, then, in every period of time $t$ a fraction of the technological gap $\Theta_{t}^{i} \in(0,1)$ can be reduced by $\vartheta \in(0,1)$ if and only if the region $i$ is innovative. Whether a region $i$ is innovative or not depends solely on a normal distributed random variable $\varpi \in[0,1]$. If this parameter $\varpi \in[0,1]$ exceeds a given threshold $\pi \in[0,1]$ then a region is innovative. In this way the tacitness of knowledge has been integrated. Remember, if $\pi \rightarrow 1$ then knowledge tends to be completely tacit and the probability of innovativeness is very small. This scenario induces a kind of knowledge which is 
hard to understand and therefore cannot be used with a high probability to reduce the technological gap. Otherwise, if $\pi \rightarrow 0$ the probability of tacit knowledge tends to zero and hence a large proportion of regions is innovative. In notational form, we can write for the technological gap $\Theta_{t}^{i}$ :

$$
\Theta_{t}^{i}:= \begin{cases}-\frac{Y_{t}^{i}-\bar{Y}_{t}}{\bar{Y}_{t}} & \text { if }: Y_{t}^{i}<\bar{Y}_{t}=\frac{1}{|H|} \sum_{j} Y_{t}^{j} \varpi>\pi \\ 0 & \text { otherwise. }\end{cases}
$$

Note that $\vartheta \in(0,1)$ and $\varpi \in[0,1]$ are treated with this formulation as global parameters. For the production of region $i$ at the beginning of the next period $t+1$ we can write $Y_{t}^{i}$ :

$$
Y_{t+1}^{i}:=\left\{\begin{array}{l}
Y_{t}^{i}+\vartheta \Theta \text { if }: \Theta>0 \\
Y_{t}^{i}, \text { otherwise. }
\end{array}\right.
$$

In this section we have defined a hybrid spatial growth model which should give a first hint of how knowledge creation, production and knowledge diffusion interact, not only in time, but also in space. As one can see, due to its complexity, this model cannot be solved analytically but numerically. The complexity stems particularly from the fact, that knowledge diffusion can be characterized with feedback rules. In the next section the simulation frame for the hybrid model is set up. Cellular Automaton $(\mathrm{CA})$ is very attractive for simulation spatial models owing due its construction.

\subsection{Cellular Automaton}

A Cellular Automaton (CA) is a simple mathematical system, which shows highly complex behavoir ${ }^{20}$. It consists, loosely spoken, of a number of cells. Every cell checks for every period of time its own and its corresponding activities of their neighbours and updates if necessary its state based on given rules. On general, a Cellular Automaton consists of a $d$-dimensional grid $D$, cells and neighbourhoods

\footnotetext{
${ }^{20}$ For an overview of Cellular Automaton please refer to (Wolfram, 1994).
} 
of cells $H$ and a transition rule $\kappa$. Usually, time is discrete and the transition rule is deterministic but may be influenced by stochastic global and local parameters $\Gamma$ and $\Phi$, respectively. The transition rule is responsible for the dynamic behaviour of the defined system.

The charme of the (CA) technique is that spatial effects or space itself can be modeled in an explicit way, because region and neighbourhood structures can be modeled. Another way of modeling space is referring on so called Agent-based modeling (ABM), which has attracted significant attention in social science during the last years. Prima vacie, (ABM) provides several advantages, such as controlling for heterogeneous entities, it encounters in fact several seriously methodological problems, especially the massive parameter space and the problem of validation. The implication of the first problem is, that we do not know which parameter settings leads to the desired behaviour of our system. Parameter setting is heuristic and not based on selection mechanism. Further, it is not possible to exclude singularities and discontinuities in the entire model space. Some regions could exhibit chaotic behaviour, whereas other regions do not. The implication of the second problem is, that it is not possible to derive an empirical model from the (ABM) structure. (CA) instead of (ABM) only provides a (spatial) framework, in which model behaviour can be discussed. As seen below, also (CA) is suitable to discuss heterogeneous phenomena.

Let us start with the definition of the dimension of $(\mathrm{CA})$. It is a regular 2-dimensional and quadratic $n \times m$ grid. Thus, we can write:

$$
D:=\left\{(i, j) \mid i, j \in \mathbb{Z}, 0 \leq i<N_{i}, 0 \leq j<N_{j}\right\}
$$

Next, we have to make some remarks regarding a given state $Z$ of our model. At first glance, we could think we could assume that the state vector $Z$ is a $\tau$-tupel and can be formulated in general as

$$
Z^{\tau}=\{0,1,2,3, \ldots, \tau-1\}
$$

But in the model context we identify several states for the variables $L, K, W$ and $Y$ due to the fact that $Z \in \mathbb{R}_{+}^{0}$. 
In this model, agglomeration of labour productivity is in the focus of investigation. Thus, if we consider a 2 dimensional grid, we can stack each region specific labour productivity $y$ in a $n \times m$ matrix $D$. In this way, it is possible to observe the evolution of labour productivity over time $t$ and over space which is defined via $D$. In this way, in every time step $t$ a Gini-coefficient with respect to $y$ with respect to regions can be computed. In addition, the evolution of spatial correlation of $y$ can be measured ${ }^{21}$.

Further, we have to consider the neighbour relationship of each cell $i$. Usually, refering on (CA) we distinguish between von-Neumann (vN) and Moore (M) non absorptive but periodic neighbourship relations. Let us define a so called immediate neighbour cell $h$ which does not consider itself as a neighbour. Thus the neighbour relations for a cell $i$ located on the two dimensional grid with coordinates $\{a, b\} \in D$ in $t$ are:

$$
i_{t}^{a, b}=\left\{\begin{array}{cc}
\left(i_{t}^{(a-1, b-1)}, i_{t}^{(a-1, b)}, i_{t}^{(a-1, b+1)}, i_{t}^{(a, b-1)}, i_{t}^{(a, b+1)}, i_{t}^{(a+1, b)}, i_{t}^{(a-1, b-1)}, i_{t}^{(a+1, b+1)}\right) & \text { if (M), } \\
\left(i_{t}^{(a-1,1)}, i_{t}^{(a, b-1)}, i_{t}^{(a, b+1)}, i_{t}^{(a+1, b)}\right) & \text { if (vN). }
\end{array} .\right.
$$

Thus, if one refers to $(\mathrm{M})$, then a region $i$ has 8 direct neighbours, whereas a $(\mathrm{vN})$ world implies 4 direct neighbours for a given region $i$ under the condition $r=1$. These different kinds of first order neighbourships $(r=1)$ can also be graphically demonstrated as in figure 1.

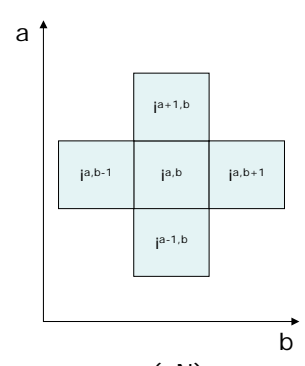

$(\mathrm{vN})$

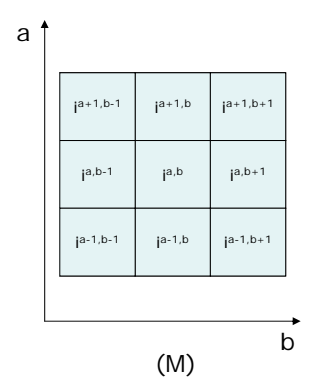

(M)

Figure 1: Representation of (vN) and (M) neighbourship relations with $(r=1)$

In this model, we rely on the Moore (M) relationship. We can see, that the (M)

\footnotetext{
${ }^{21}$ With Matlab 6.5.0 one can visualize this simulation experiment with spy(D) for instance.
} 
relationship builds a "ring" of neighbours with radius $r=1$ round the cell of interest $i^{a, b}$. At this point, it should be kept in mind, that we have to integrate assumption 4 in our model, which means that we have think about a more explicit space dependency. The easiest way to do this, is to create a second ring round the neighbour cell $i^{a, b}$ with radius $r=2$. Of course, one can go further to integrate higher degrees of $r$, but this should be enough do see the difference if one acknowledges the so called "neighbours of neighbours" influence. On general, we can write for $r=\{1,2, \ldots, R\}$ :

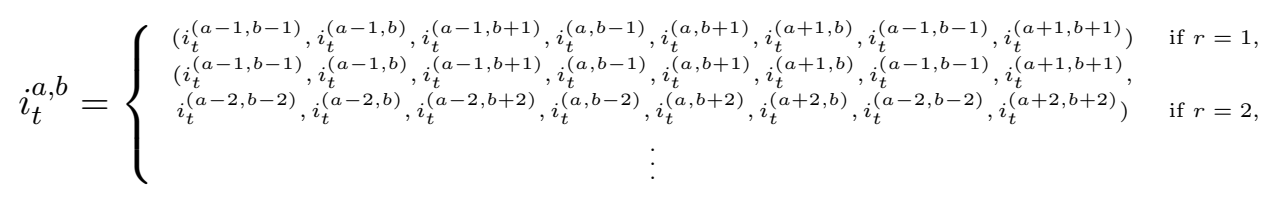

Thus with this notation the (CA) represents an economy which is divided into several regions and which allocates an identical number of neighbours to each region. We can therefore represent the economy as a so called circular city. ${ }^{22}$

As mentioned, it is assumed that spillovers are not treated as constant over space and further it is assumed that they are limited over space. More concrete a region $i$ benefits more from the nearest regions than from farther away regions regarding knowledge spillovers. Thus we have to introduce a spatial weighting scheme of neighbourhood potential regarding. Further, we have to acknowledge own effects of a given region $i$. In this way, we have to discriminate region specific effects and neighbour effects which affects a given knowledge specific economic variable $\tilde{V}_{t}^{i} \in \mathbb{R}_{0}^{+}$. Label $V_{t}^{\text {spill }}$ the spillover potential of neighbourhood and $V_{t}^{i}$ the region specific economic variable then overall effect can be written as

$$
\begin{aligned}
\tilde{V}_{t}^{i} & =\left[\left(\xi^{1} \sum_{k \in N_{j}^{1}} V_{t}^{k}+\xi^{2} \sum_{k \in N_{j}^{2}} V_{t}^{k}+\ldots+\xi^{R} \sum_{k \in N_{j}^{R}} V_{t}^{k}\right)+V_{t}^{i}\right] \\
& =\left[V_{t}^{\text {spill }}+V_{t}^{i}\right]
\end{aligned}
$$

with $\xi^{1} \geq \xi^{1} \geq \ldots \geq \xi^{R}$, and $N_{i, j}^{r} \subset N_{i, j}$ for $r=\{1,2, \ldots, R\}$ and $\xi^{r} \in(0,1)$ which act as a weighting parameter for higher order neighbour influence. If $r=1$ only nearest

\footnotetext{
${ }^{22}$ Refer to (Tirole, 1988), (Hotelling, 1929) and (Krugman, 1995).
} 
neighbour relations matter. The latter assumption is the common assumption which has been made in empirical literature when talking about spatial effects.

Now we are able to set up the dynamic behaviour of the CA. For that purpose, we need a mapping scheme to integrate the dynamics into our system. Please note, that a given variable $Z_{t}$ is endogenous because it is influenced through the neighbours $H_{t}$ and global and local parameters $\Phi_{t}$ and $\Psi_{t}{ }^{23}$. Therefore, let us write $Z_{t}\left(H_{t}, \Psi_{t}, \Phi_{t}\right)^{24}$ To map the dynamics a mapping function $\kappa$ is required. This function reads as follows:

$$
\kappa:=Z_{t}^{H_{t}} \rightarrow Z_{t+1}
$$

\subsection{Model simulation}

As easily can be seen from above, the model is not restricted to have constant returns to scale, which means that $\alpha+\beta=1$ and $\gamma+\psi+\kappa=1$. For instance, if the goods sector exhibits increasing returns to scale $\alpha+\beta>1$ even in a competitive environment, if knowledge spillovers are introduced as done by (Lucas, 1988). As known, the results obtained in a competitive environment are generally not Pareto optimal. In this case, governmental subsidize schemes have to be initialized to subsidize activities with positive spillovers. Further it should be noted, that large spillovers could create multiple equilibria which can be ranked by the Pareto criterion. ${ }^{25}$

As highlighted by (Lucas, 1988) knowledge spillovers lead to increasing returns to scale in the goods sector. Of course, such a condition is compatible with endogenous growth, but it is not a necessary condition. The model of (Lucas, 1988) can also generate endogenous growth without knowledge spillovers from knowledge sector. Although, the focus on this analysis is not in first line tend to discuss the conditions of endogenous growth in this model framework, this should fact should be kept in mind.

If we turn back to our simulation exercise and if we further follow (Eicher and Turnovsky, 1999), three simulation scenarios are distinguished: first, both the goods

\footnotetext{
${ }^{23}$ The vectors contain the depreciation rate, the saving rate etc..

${ }^{24} \Phi$ and $\Psi$ may be time variant or not.

${ }^{25}$ Refer to (Barro and Sala-I-Martin, 1995), p. 199.
} 
sector and the knowledge good sector exhibit increasing return to scales, second, the goods sector and the knowledge good sector exhibit constant return to scales, and third, both sectors exhibit decreasing return to scales. All scenarios are run for first order and second order spatial influence.

For the simulation study, it is assumed, that labour is mobile, which means that $\theta>0$ and it is growing with a constant rate $g_{L}$. Further it is assumed, that capital is mobile and capital restrictions are close to zero $(\varphi=0.99)$. For the capital adjustment costs a value of $\rho=0.5$ has been chosen. The savings rate is set to $s=0.10$ which reflects a ten year average saving rate for Germany ${ }^{26}$. It is further assumed that in every period the technological gap of a region $i$ can be reduced by $\vartheta=0.10$. This is a very small value, but it is in line with the assumption that knowledge is tacit which means that $\pi=0.8$. Furthermore, first order $(r=1)$ and second order influence of neighbourhood $(r=2)$ is not constant over space but decreasing, hence we set $\xi=0.1$.

Values for elasticities of production have been chosen according to the works of (Lucas, 1988) and (Jones, 1995). Data for depreciation rates both for human and physical capital have been taken from (Kydland and Prescott, 1982). Table 1 in the appendix provides a summary of the parameter settings.

Further, one has to choose arbitrary starting values for the stock of knowledge, labour and capital. With the exception of knowledge $W_{0}$, which is random and distributed uniformly in the interval $[0,0.5]$ all variables of interest are set to $K_{0}=$ $L_{0}=1$ for all regions $i$. Thus, the regions differ only with their initial endowment of knowledge $W_{0}^{i} \neq W_{0}^{j}$.

\subsection{Simulation results}

This section provides an overview of the simulation results. Results are presented both for first order $(r=1)$ and second order $(r=2)$ spatial influence. Simulations have been performed using Matlab 6.5.0. ${ }^{27}$

\footnotetext{
${ }^{26}$ Refer to the homepage of "Statistische Bundesamt": http://www.destatis.de for further information regarding the development of the German saving rate.

${ }^{27}$ The program is available on request.
} 


\subsubsection{First order spatial influence}

The first simulation has been run for the case of decreasing return to scales (DRS) scenario. As we can see from figure 2 we we do not observe an agglomeration tendency for this case after 200 periods. ${ }^{28}$ As a consequence of that, the Gini-coefficient as well as the spatial concentration should be rather low for labour productivity, which can be seen from figure 2. As a result, decreasing returns to scale do not display relevant agglomeration tendencies within our framework.

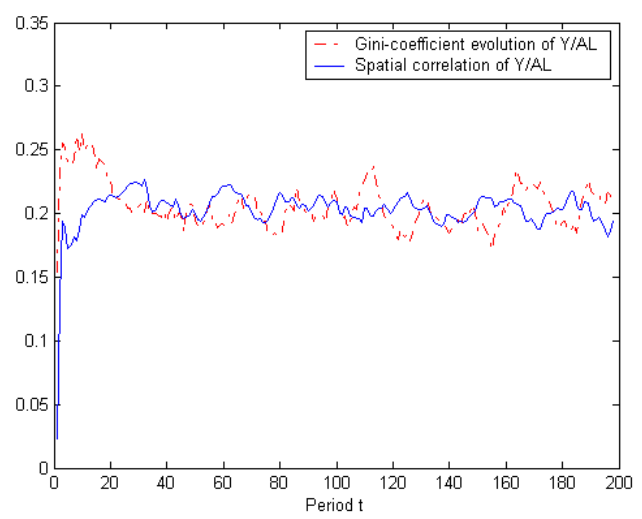

Figure 2: Evolution of Gini-coefficient and spatial correlation of $\frac{Y}{A L}$ for DRS and $r=1$

For the second simulation (figure 3) we assume constant returns to scale (CRS). On contrary to the before discussed case, we observe a spatial concentration of the per capita income after 200 iteration steps. The Gini-coefficient exhibits a higher value on average compared to the DRS scenario, which means that distribution of per capita income tends to be more unequal as in the DRS scenario.

The last simulation (figure 4) has been done for the increasing return to scales case (IRS). The conspicuous fact is, that we can observe a strong agglomeration tendency right from the beginning of the simulation. After 200 simulation runs we observe only a few regions which exhibit a high per capita income relative to the rest of the world. This is in line with the fact that the Gini-coefficient indicates a strong

\footnotetext{
${ }^{28}$ Spatial correlation is measured similarly to time series analysis context with the so called Moran's- $\mathcal{I}$.
} 


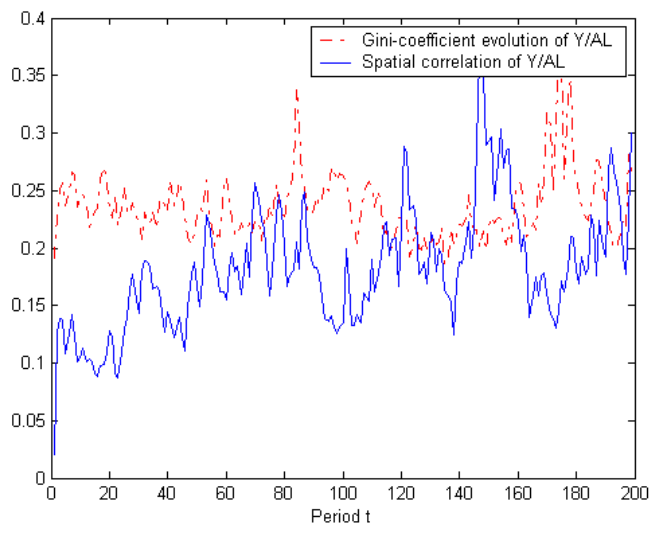

Figure 3: Evolution of Gini-coefficient and spatial correlation of $\frac{Y}{A L}$ for CRS and $r=1$

uneven income per capita distribution.

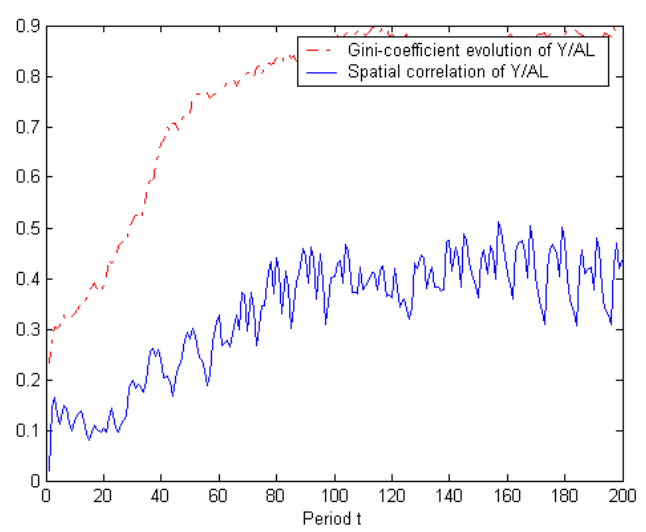

Figure 4: Evolution of Gini-coefficient and spatial correlation of $\frac{Y}{A L}$ for IRS and $r=1$

\subsubsection{Second order spatial influence}

In this section, we perform the same simulations as done before in section $\mathrm{xx}$ with respect to the fact that second order neighbour influence matters. The intuition is, that second order spatial influence leads to a stronger spatial correlation of per capita income, because of the fact, that more regions benefits from knowledge spillovers. Further, the Gini-coefficient should exhibit a more equal distribution, also due the 
fact, that more regions can benefit from knowledge spillover pool. Simulation scenarios can be found in figures 5,6 and 7 .

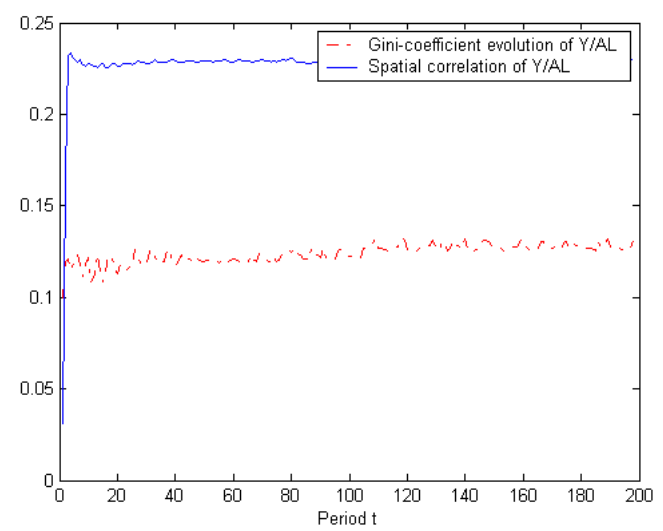

Figure 5: Evolution of Gini-coefficient and spatial correlation of $\frac{Y}{A L}$ for DRS and $r=2$

First, the simulation of the DRS case has been performed. Compared to DRS scenario with $r=1$, we observe, that spatial correlation is higher but at the same time income per capita is more evenly distributed as for the case of first order spatial effects.

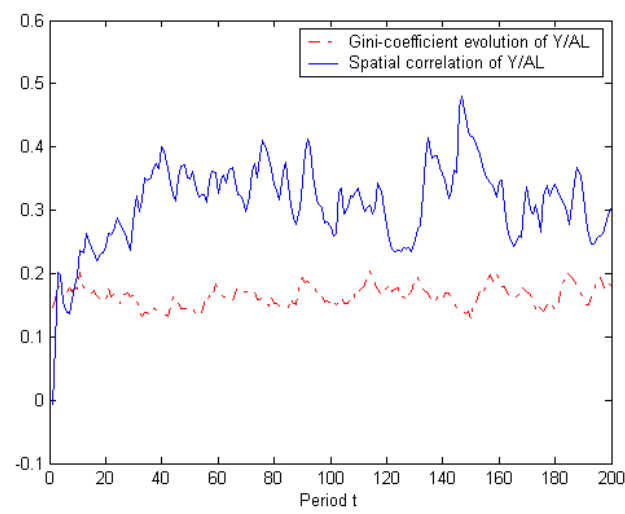

Figure 6: Evolution of Gini-coefficient and spatial correlation of $\frac{Y}{A L}$ for CRS and $r=2$

Second, if we compare the CRS scenario for $r=1$ with the CRS scenario with $r=2$ 
we conclude, that income per capita distribution is more evenly distributed for the case of second order spatial influence.

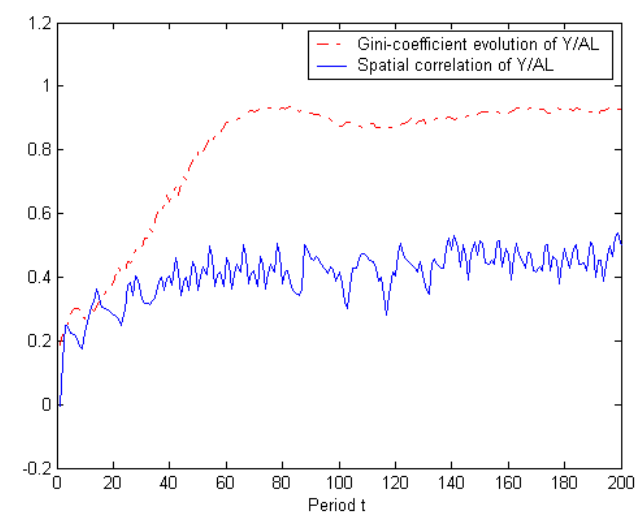

Figure 7: Evolution of Gini-coefficient and spatial correlation of $\frac{Y}{A L}$ for IRS and $r=2$

Third, only for the IRS case, we observe no relevant differences between the first and second order spatial influence scenario. Although the obtained results are based on one particular parameter constellation, unreported sensitivity analysis indicate that the obtained results hold more generally.

\subsection{Conclusion}

The aim of the model derived above is to investigate the relationship between knowledge diffusion, agglomeration and growth. From a theoretical growth literature view, only the link of technological innovations and knowledge diffusion for technological growth is widely discussed ${ }^{29}$, while the role of knowledge diffusion is only partly considered. Ex ante, the so called North-South trade model seems appropriate to cope with this research question. Some of the North-South trade literature on diffusion and technological progress ${ }^{30}$ consider feedback effects between the North and

\footnotetext{
${ }^{29}$ Refer to (Romer, 1986), (Romer, 1990) and (Krugman, 1991) for instance.

${ }^{30}$ Refer to (Krugman, 1979), (Dollar, 1986), (Grossman and Helpman, 1991b), (Grossman and Helpman, 1991a), (Rivera-Batiz and Romer, 1991), (Barro and Sala-I-Martin, 1997) and (Glass, 1997).
} 
the South in the steady state, but an analysis of the transitional dynamics for either region is missing. (Barro and Sala-I-Martin, 1997) indeed derived transitional dynamics for the South but feedback effects are excluded as there is no trade of intermediate goods. Thus, a transition path for the North cannot be derived.

The communality of this strand of literature is only focused on two country or two region models, which consist of a rich North and a poor South or a core and a peripheral country. From this perspective, those type of models are less suitable to investigate the link of increasing returns to scale, agglomeration and distribution of economic numbers because in a two country framework, it is not reasonable for instance to investigate agglomeration effects over regions. From this point of view, those North-South models are not appropriate to give a justification of the "folk theorem of spatial economics" which states that increasing returns to scale are essential for explaining agglomeration effects and thus uneven geographical distribution of economic numbers.

To investigate the relationship between knowledge diffusion, agglomeration and growth one has to refer to a multi country framework. One of the reasons, why multiple country or regional focused growth models are less attractive could be that such growth models become very complex and cannot solved analytically. For computational reason, a Cellular Automaton framework has been used to simulate the before established model. This environment has been selected because of its ability to visualize spatial effects. ${ }^{31}$.

The aim of the theoretically derived model, which is based on the works of (Uzawa, 1965) and (Lucas, 1988), is to derive a theoretical growth orientated justification of the "folk theorem of spatial economics" 32 , that "increasing returns to scale (IRS) are essential for explaining geographical distributions of economic activities" 33 . For this reason, a world consisting of 100 regions has been simulated to study the effects of decreasing returns to scale, constant returns to scale and increasing returns to scale, both in the goods sector and in the R\&D sector on the per capita production

\footnotetext{
${ }^{31}$ Refer to (Keilbach, 2000).

${ }^{32}$ Refer to (Scotchmer and Thisse, 1992).

${ }^{33}$ (Fujita and Thisse, 2002), p. 342.
} 
in each region. To measure inequality over regions, we refer to the Gini-coefficient. Further it was distinguished between first order and second order spatial effects to control for different grasps of knowledge spillover.

After performing two simulation scenarios, it was found that productivity is more evenly distributed the higher the degree of spatial effects is, et vice versa. Second, spatial dependence is higher, the higher the degree of spatial effects is. Third, a strong unevenly productivity distribution results only for the case of increasing returns to scale, for any degree of spatial effects. Thus, the "folk theorem of spatial economics"' seems to be justified within this model framework.

Of course, there are various avenues for further research. One of the possible research fields is, to embed the (CA) modelling technique in a general equilibrium framework. Further, the question how (weak) scale effects in per capita production affects the per capita production distribution of regions should be investigated deeper in further research. 


\section{$3 \quad$ Appendix}

\begin{tabular}{ccccc}
\hline \hline Sector & Parameter & CRS & DRS & IRS \\
\hline Good sector & $\alpha$ & 0.360 & 0.300 & 0.400 \\
Good sector & $\beta$ & 0.640 & 0.500 & 0.700 \\
Good sector & $\left(1-\mathrm{a}_{K}\right)$ & 0.500 & 0.500 & 0.500 \\
Good sector & $\left(1-\mathrm{a}_{W}\right)$ & 0.500 & 0.500 & 0.500 \\
Good sector & $\vartheta$ & 0.100 & 0.100 & 0.100 \\
Good sector & $\pi$ & 0.800 & 0.800 & 0.800 \\
\hline Knowledge sector & $\gamma$ & 0.100 & 0.100 & 0.100 \\
Knowledge sector & $\phi$ & 0.300 & 0.200 & 0.400 \\
Knowledge sector & $\kappa$ & 0.600 & 0.200 & 0.600 \\
Knowledge sector & $\mathrm{a}_{K}$ & 0.500 & 0.500 & 0.500 \\
Knowledge sector & $\mathrm{a}_{W}$ & 0.500 & 0.500 & 0.500 \\
Knowledge sector & $\delta_{W}$ & 0.005 & 0.005 & 0.005 \\
\hline Capital market & $\delta_{K}$ & 0.025 & 0.025 & 0.025 \\
Capital market & $\zeta$ & 0.500 & 0.500 & 0.500 \\
Capital market & $\varphi$ & 0.990 & 0.990 & 0.990 \\
\hline Labour market & $\theta$ & 0.300 & 0.300 & 0.300 \\
Labour market & $\mathrm{g}_{A}$ & 0.001 & 0.001 & 0.001 \\
Labour market & $\mathrm{g}_{N}$ & 0.001 & 0.001 & 0.001 \\
\hline Neighbour relations & $\xi$ & 0.100 & 0.100 & 0.100 \\
Neighbour relations & $\mathrm{r}$ & $1 / 2$ & $1 / 2$ & $1 / 2$ \\
\hline \hline
\end{tabular}

Table 1: Parameter setting 


\section{References}

Anselin, L. (1988). Spatial Econometrics: Methods and Models. Dordrecht.

Anselin, L., Varga, A., and Acs, Z. (1997). Local Geographic Spillovers between University Research and High-Technology Innovations. In: Journal of Urban Economics, 42, pp. 422-448.

Audretsch, D. and Mahmood, T. (1994). The Knowledge Production Function and $R \& D$ Spillovers. Wissenschaftszentrum Berlin für Sozialforschung. Discussion Paper FS IV 94-6.

Baldwin, R. E. and Martin, P. (2003). Agglomeration and Regional Growth. CEPR Discussion Paper No. 3960.

Barro, R. J. and Sala-I-Martin, X. (1995). Economic Growth. New-York.

Barro, R. J. and Sala-I-Martin, X. (1997). Technological diffusion, convergence, and growth. In: Journal of Economic Growth, 2, pp. 126.

Bottazzi, L. and Peri, G. (2003). Innovation and spillovers in regions: evidence from European patent data. In: European Economic Review, 47, pp. 687-710.

Brezis, E. S. and Krugman, P. (1993). Technology and the Life-Cycle of Cities. NBER Working Paper, No. 4561.

Dollar, D. (1986). Technological innovation, capital mobility, and the product cycle in North-South trade. In: The American Economic Review, 76, pp. 177-190.

Eicher, T. S. and Turnovsky, S. J. (1999). Convergence in a Two-Sector Nonscale Growth Model. In: Journal of Economic Growth, 4, pp. 413-428.

Florax, R. J. G. M., Folmer, H., and Rey, S. J. (2003). Specification searches in spatial econometrics: the relevance of Hendry's methodology. In: Regional Science and Urban Economics, 33, pp. 557-579.

Frauenhofer (2000). Regionale Verteilung von Innovations- und Technologiepotentialen in Deutschland und Europa. Fraunhofer-Institut für Systemtechnik und Innovationsforschung, Karlsruhe. 
Fujita, M. and Thisse, J. (2002). Economics of Agglomeration. Cambridge.

Glass, A. (1997). Product cycles and market penetration. In: International Economic Review, 38, pp. 865-891.

Greif, S. (1998). Patentatlas Deutschland. München.

Griliches, Z. (1979). Issues in Assessing the Contribution of Research and Development to Productivity Growth. In: The Bell Journal of Economics, 10, pp. 92-116.

Grossman, G. M. and Helpman, E. (1991a). Innovation and Growth in the Global Economy. Cambridge.

Grossman, G. M. and Helpman, E. (1991b). Quality ladders and product cycles. In: The Quarterly Journal of Economics, 106, pp. 557-586.

Hendry, D. F. (1979). Predictive failure and econometric modelling in macroeconomics: The transactions demand for money. In: P. Ormerod (ed.), Economic Modelling. London.

Hendry, D. F. (2006). A comment on specification searches in spatial econometrics: The relevance of Hendrys methodology. In: Regional Science and Urban Economics, 36, pp. 309-312.

Hotelling, H. (1929). Stability in competition. In: The Economic Journal, 39, pp. 41-57.

Jones, C. (1995). R\&D Based Models of Economic Growth. In: Journal of Political Economics, 103, pp. 759-784.

Kahnert, R. (1998). Wirtschaftsentwicklung, Sub- und Desuburbanisierung. In: Informationen zur Raumentwicklung, 24, pp. 509-520.

Keilbach, M. (2000). Spatial Knowledge Spillovers and the Dynamic of Agglomeration and Regional Growth. Heidelberg.

Krugman, P. (1979). A model of innovation, technology transfer, and the world distribution of income. In: Journal of Political Economy, 87, pp. 253-266. 
Krugman, P. (1991). Increasing Returns and Economic Geography. In: Journal of Political Economy, 99, pp. 483-499.

Krugman, P. (1995). Development, Geography and Economic Theory. Cambridge.

Krugman, P. (1998a). Space: The Final Frontier. In: Journal of Economic Perspectives, 12 , pp. 161-174.

Krugman, P. (1998b). Whats New About New Economic Geography? In: Oxford Review of Economic Policy, 14, pp. 7-17.

Kydland, F. E. and Prescott, E. C. (1982). Time to build and aggregate fluctuations. In: Econometrica, 50, p. 1345-70.

Lucas, R. E. (1988). On the Mechanics of Economic Development. In: Journal of Monetary Economics, 22, p. 3-39.

Marshall, A. (1920). Principles of Economics. 8th edition. London.

Maskell, P. and Malmberg, A. (1999). Localised learning and industrial competitiveness. In: Cambridge Journal of Economics, 23, p. 167-185.

Morgan, K. (1997). The learning region: institutions, innovation and regional renewal. In: Regional Studies, 31, pp. 491-503.

Mulligan, C. B. and Sala-I-Martin, X. (1993). Transitional Dynamics in Two-Sector Models of Endogenous Growth. In: Quarterly Journal of Economics, 108, pp. 739-73.

Rivera-Batiz, L. A. and Romer, P. M. (1991). International trade with endogenous technological change. In: Economic Review, 35, pp. 971-1004.

Romer, P. (1986). Increasing Returns and Long-Run Growth. In: Journal of Political Economy, 94, pp. 1002-1037.

Romer, P. (1990). Endogenous Technical Change. In: Journal of Political Economy, 98, pp. 71-102.

Rosenberg, N. (1982). Inside the Black Box: Technology and Economics. Cambridge. 
Scotchmer, S. and Thisse, J.-F. (1992). Space and Competition: A Puzzle. In: Annals of Regional Science, 26, pp. 269-286.

Tirole, J. (1988). The Theory of Industrial Organization. Cambridge.

Uzawa, H. (1965). Optimum Technical Change in an Aggregative Model of Economic Growth. In: International Economic Review, 6, pp. 18-31.

Wolfram, S. (1994). Cellular Automata and Complexity. Reading. 